\title{
Gender disparities of chronic musculoskeletal disorder burden in the elderly Ghanaian population: study on global ageing and adult health (SAGE WAVE 1)
}

Emmanuel Kweku Nakua ${ }^{{ }^{*}+}$, Easmon Otupiri ${ }^{1 \dagger}$, Veronica Millicent Dzomeku ${ }^{2 \dagger}$, Ellis Owusu-Dabo ${ }^{3,4 \dagger}$, Peter Agyei-Baffour ${ }^{5}$, Alfred Edwin Yawson ${ }^{6+}$, Gloria Folson ${ }^{7}$ and Sandra Hewlett ${ }^{8}$

\begin{abstract}
Background: Traditionally, non-communicable diseases including musculoskeletal disorders have not been a priority in low-and-middle income countries. The main aim of this paper is to assess age and gender specific burden by estimating the current prevalence of musculoskeletal disorders and associated risk factors in the elderly Ghanaian population.

Methods: Between May 2007 and June 2008, the World Health Organization conducted a nationwide study on AGEing (SAGE) and Adult Health in Ghana. The study employed a multistage cluster sampling strategy to identify participants by stratifying the population by age and setting. A structured questionnaire was used for data collection. A Poisson regression model was fitted with robust error variance. Prevalence estimates took into account the complex survey design and sampling weights. Statistical significance was considered at $p \leq 0.05$ significance level. Statistical analysis was performed with STATA version 11.2.

Results: The prevalence rates of chronic back pain and chronic arthritis/joints pain were higher in women than men. The overall crude prevalence's rates were 28.2 and $10.7 \%$ for chronic back pain and chronic arthritis/joints pain respectively. Substantial differences existed between men and women in terms of socio-economic status, education level and occupational status. Women with primary education had a chronic back pain prevalence of $36.2 \%$ ( $95 \% \mathrm{Cl} ; 29.2,43.3)$ and chronic arthritis/joints pain prevalence of $15.8 \%(95 \% \mathrm{Cl} ; 11.1,20.6)$ while their male counterparts had prevalence rates of $29.0 \%(95 \% \mathrm{Cl} ; 23.4,34.5)$ and $9.8 \%(95 \% \mathrm{Cl} ; 6.4,13.2)$ respectively. Residence (rural and urban) did not appear to influence the prevalence of chronic back pain and arthritis/joints pain.

Conclusion: Our findings suggest the existence of sex differences in chronic back pain and chronic arthritis/joint pain in the elderly population in Ghana after adjustment for demographic and socio-economic factors. It indicates the existence of inequalities in health between elderly men and women with women suffering more from chronic back pain and chronic arthritis/joints pain.
\end{abstract}

\footnotetext{
* Correspondence: emmanngh@gmail.com

${ }^{\dagger}$ Equal contributors

'Department of Population, Family and Reproductive Health, School of Public Health, Kwame Nkrumah University Science and Technology, Kumasi,

Ghana

Full list of author information is available at the end of the article
}

\section{Biomed Central}

(C) 2015 Nakua et al. Open Access This article is distributed under the terms of the Creative Commons Attribution 4.0 International License (http://creativecommons.org/licenses/by/4.0/), which permits unrestricted use, distribution, and reproduction in any medium, provided you give appropriate credit to the original author(s) and the source, provide a link to the Creative Commons license, and indicate if changes were made. The Creative Commons Public Domain Dedication waiver (http://creativecommons.org/publicdomain/zero/1.0/) applies to the data made available in this article, unless otherwise stated. 


\section{Background}

Due to the nagging effects of chronic diseases on the quality of life, chronic diseases remain a relevant public health problem and a medical challenge, with long term disability adjusted life years in both developed and developing countries. Per the United Nations (UN) estimates, the proportion of older people is expected to triple over the next 40 years, accounting for more than $20 \%$ of the world's population by the year 2050 [1]. The expected exponential increase in the elderly population would mainly be a product of rise in life expectancy, especially in developing countries. The associated rise is the incidence of non-communicable chronic conditions with consequent increase in morbidity and disability [2]. Chronic conditions impact heavily on economic productivity of families and have wider costs to health and social services [3].

Musculoskeletal disorders (MSD) are observed to be prevalent with pervasive impact especially in the elderly. They are the most common cause of severe long-term pain and physical disability, and affect hundreds of millions of people around the world [4]. MSD pain causes decreased quality of life among individuals, limits activity, and reduces functional capacity. To society, pain translates into considerable financial burden causing increased use of health services and medication, sickness absence and early retirement $[5,6]$. Previous studies have emphasised the global magnitude of this problem. Mantyselka et al. (2001) concluded in their study that about $35 \%$ of the Finnish population reported chronic pain; $40 \%$ of all visits to general practitioners in this population is caused by pain [6]. A similar study in the United Kingdom showed that $79 \%$ of those having chronic pain continued to suffer from the pain 4 years on. The annual recovery rate was only $5 \%$ [7]. MSD, is ranked number one in chronic impairments in the United States and 1 out of every 4 people in developed and less developed countries reports chronic musculoskeletal pain [8]. There is however statistical dearth in terms of rates and other epidemiological measures of diseases in the developing world.

A number of population surveys have estimated the prevalence of individual musculoskeletal symptoms although accuracy in measurement remains a difficult challenge [9]. Fewer studies have however, considered the relative frequency of musculoskeletal disorders by gender. Those that have, suggest a considerable degree of overlap. The need for socio-economic factors to be considered also arises since they are known to play an important part in the occurrence of back pain, arthritis/ joints pain and some general musculoskeletal disorders. The role of socio-economic factors in musculoskeletal disorders cannot be placed in the realm of oblivion and thus have to be explored fully. Traditionally, public health priorities have been assessed mainly by mortality statistics. In rapidly ageing populations, particularly those in developing countries, mortality statistics tend to be inaccurate or incomplete, and do not reflect those conditions that do not cause death but contribute chiefly to morbidity and disability [10].

The main aim of this paper is to estimate the current prevalence of musculoskeletal disorders in the elderly population in Ghana. The article also seeks to assess the level of socio-economic related inequality in the prevalence of MSD, and to suggest the extent and direction of equity in health care provision with respect to socioeconomic deprivation in providing evidence to guide the implementation of the National Ageing policy of 2010 to addressing this health burden in Ghana.

\section{Methods}

\section{Sample}

The data were obtained from the World Health Organization Study on Global AGEing (SAGE) and Adult Health survey conducted from May 2007 to June 2008. The aim of this multi-country study was to fill the data gaps for the older population in lowto-middle income countries.

SAGE is a longitudinal study with national representation and probabilistically selected. The study sampled persons aged 50+ years in Ghana, with comparison samples of young adult's age 18-49 years in each country. The study employed a multistage cluster sampling strategy to identify participants and stratified by administrative region (Ashanti, Brong Ahafo, Central, Eastern, Greater Accra, Northern, Upper East, Upper West, Volta and Western) and setting (rural/urban), resulting in 20 strata. A total of 10-15 Enumeration Areas (EA) were selected from the strata according to size. Twenty households with persons aged 50 years and four households with person's aged 18-49 years were then selected for interview. All persons aged 50-plus in 'older' households (households with at least one person age 50-plus years) were recruited to participate, whereas only one person was randomly selected in 'younger' households (households with no person aged 50-plus years) for the individual interview. If a selected individual was found to be incapable of completing an interview for reasons of health or cognition, a proxy questionnaire was completed. Standardized training in all aspects of the interview was provided to all interviewers. The survey was implemented as face-to-face interviews. Detailed sampling procedures have been explained in a methodology paper by Kowal et al., 2012 [11]. The questions related to MSD aimed at identifying socio-demographic and economic characteristics as well as symptoms of chronic diseases including back pain, arthritis/joints pain and general chronic pains were asked. Data were 
collected by means of a structured questionnaire. Ethical clearance was provided by the WHO as well as the Ethical and Protocol Review Committee of the University of Ghana Medical School. Informed consent was obtained from all participants.

\section{Outcome measures}

The outcome variables in this analysis were based on self-reported chronic health conditions by respondents. Back pain and arthritis/joint pain were the two outcomes of interest. Pains related to injuries from accidents such as falls, struck/hit by falling object and road traffic accidents by person were excluded. For each of these outcomes information of pain status was elicited either in two or more questions. Respondents were first asked whether they had been diagnosed with arthritis (a disease of the joints, or by other names rheumatism or osteoarthritis) and had sought medication for the last 12 months (yes/no) including the last 2 weeks. Respondents were then asked whether they had experienced back pain and the number of days it lasted during the last 30 days. Answers were dichotomized as the presence or absence of self-reported symptoms. To classify the back pain and arthritis/joints pain as chronic or other, a question on whether a respondent's visit to health care provider was for a chronic (ongoing) condition, new condition, both or routine check-up was asked. Pain status was only classified as chronic pain if the visit was for an ongoing condition all new cases were excluded.

Covariates Sex, age (50-59, 60-69, 70-79 and 80+ years) and marital status (never married, currently married/cohabitating, separated/divorced, widows) were some sociodemographic variables of interest. The questionnaire collected information on the work history of the respondents whether the respondent has ever worked for pay, type of work, place of work and for how long the respondent worked. The type of work of the respondents was classified using the International Standard Classification of Occupation (ISCO-88) [12]. The ISCO-88 has nine (9) categories (1. Legislators, senior officials and managers, 2. Professionals, 3. Technicians and associate professionals, 4. Clerks, 5. Service workers and shop and marker sales workers, 6. Skilled agricultural and fishery workers, 7. Craft and related workers, 8. Plant and machine operators and assemblers and 9. Elementary occupations) but for the purposes of this paper, the categories were re-grouped into four categories (Professional, Technical, Skilled agricultural and fishery workers, and Elementary occupation). Also considered were education (no formal education and some formal education), and wealth quintiles (poorest, poor, middle, and upper fifth and wealthiest) estimated from the household assets using the principal component analysis. The characteristics of men and women were compared by residence.

Statistical analysis The percentage distribution of socio-demographic and socio-economic variables by sex and by setting (urban/ rural) was estimated as well as the prevalence of chronic back pain and arthritis/joint pains. Prevalence were estimated by setting as well as age-adjusted rates with $95 \%$ confidence intervals $(\mathrm{CI})$ estimated using the population structure of Ghana for the 2010 population census as the standard [13]. This analysis was restricted to respondents who had arthritis/joints pain or back pain, and who had sought treatment from the health facility for a chronic pain. A Poisson regression model was fitted with robust error variance. This regression technique allows for a conservative estimation of the relative risk when the outcome of interest occurs more than $10 \%$ of the time, as in the case of back pain and arthritis/joints pain in this analysis [14]. Univariate analysis for each of the covariates was fitted. In the multivariate analysis, forward stepwise and backward stepwise models were performed. The result from the backward stepwise model was adopted. Models were fitted separately for each of the two outcome variables (chronic arthritis/joints pain and chronic back pain). Respondents who did not experience chronic back pain or chronic arthritis/joints pain were considered as the reference group for comparison with the disease outcome. Prevalence estimates took into account the complex survey design and sampling weights. Statistical significance was considered at $\mathrm{p} \leq$ 0.05 significance level. STATA version eleven (11.2) (Stata Corp., College Station, Texas: StataCorp LP, USA) was used for all statistical analyses.

\section{Results}

Table 1 presents the demographic and socio-economic characteristics of the study sample. From the sample, 1 925 were resident in rural areas while 2799 were in urban areas. Similar mean age distribution was observed among rural men and women, while in the urban areas men were slightly younger. Majority of elderly men and women had no formal education; however it was observed to a greater extent in rural and urban women than men; $78.8 \%$ versus $53.7 \%$ (for rural women and men) and $60.4 \%$ versus $36.0 \%$ (for urban women and men).

With the marital status variable, currently married/cohabiting was prevalent for men living in both rural $(84.0 \%)$ and urban $(82.1 \%)$ areas while their women counterparts in both areas were more likely to be widowed. Skilled agricultural and fishery was predominant 
Table 1 Demographic and socioeconomic characteristics by sex in urban and rural areas for the elderly population

\begin{tabular}{|c|c|c|c|c|}
\hline \multirow[b]{2}{*}{ Socioeconomic variables } & \multicolumn{2}{|l|}{$\operatorname{Rural}(N=2,799)$} & \multicolumn{2}{|l|}{ Urban $(1,925)$} \\
\hline & Women(1333) \% & Men(1466) \% & Women(1 044) \% & Men(881) \% \\
\hline Mean age in years $(95 \% \mathrm{Cl})$ & $64.9(64.4,65.5)$ & $64.1(63.6,64.7)$ & $64.7(64.0,65.4)$ & $62.65(62.0,63.3)$ \\
\hline \multicolumn{5}{|l|}{ Age group (years) } \\
\hline $50-59$ & 36.2 & 39.0 & 39.5 & 47.2 \\
\hline $60-69$ & 26.3 & 29.8 & 26.0 & 28.4 \\
\hline $70-79$ & 27.2 & 21.1 & 23.4 & 17.4 \\
\hline $80+$ & 10.3 & 10.2 & 11.2 & 7.0 \\
\hline \multicolumn{5}{|l|}{ Educational level } \\
\hline No formal education & 78.8 & 53.7 & 60.4 & 35.0 \\
\hline Primary Education & 14.5 & 22.1 & 19.4 & 19.8 \\
\hline Secondary education & 5.9 & 20.7 & 16.8 & 36.4 \\
\hline University/postgraduate & 0.5 & 2.7 & 3.1 & 8.2 \\
\hline Missing & 0.3 & 0.8 & 0.3 & 0.6 \\
\hline \multicolumn{5}{|l|}{ Marital Status } \\
\hline Never Married & 0.9 & 1.2 & 1.8 & 1.1 \\
\hline Currently married/Cohabiting & 36.0 & 84.0 & 29.2 & 82.1 \\
\hline Separated/Divorced & 16.4 & 7.4 & 20.5 & 9.3 \\
\hline Widowed & 46.0 & 7.0 & 47.8 & 6.8 \\
\hline Missing & 0.6 & 0.4 & 0.7 & 0.7 \\
\hline \multicolumn{5}{|l|}{ Type of Work ${ }^{a}$} \\
\hline Professional & 0.2 & 1.2 & 1.3 & 5.2 \\
\hline Skilled agricultural and fishery workers & 67.4 & 82.5 & 42.4 & 61.0 \\
\hline Technical & 4.6 & 5.1 & 10.3 & 13.5 \\
\hline Elementary occupation & 10.2 & 2.2 & 29.1 & 10.1 \\
\hline Missing & 17.7 & 9.1 & 16.9 & 10.2 \\
\hline \multicolumn{5}{|l|}{ Socio-economic status } \\
\hline Poorest & 27.5 & 27.0 & 11.8 & 6.0 \\
\hline Poor & 27.2 & 22.9 & 14.0 & 10.8 \\
\hline Middle & 23.3 & 22.4 & 17.1 & 15.0 \\
\hline Upper fifth & 15.3 & 17.5 & 24.6 & 24.4 \\
\hline Wealthiest & 6.6 & 10.2 & 32.2 & 43.6 \\
\hline Missing & 0.1 & 0.0 & 0.4 & 0.2 \\
\hline
\end{tabular}

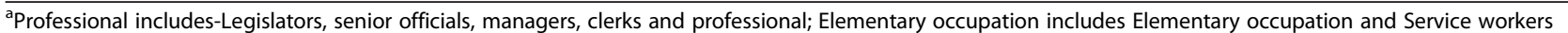
and shop and market, Technical includes-Technicians and associate professionals, Craft and related trades workers, and Plant and machine operators and assemblers

in both rural and urban settings for both men and women. In the urban areas, there were more women (23.6 \%) working in the public sector compared with men (7.3\%). Majority of people in the rural areas were found in the poorest quintile and these proportions were similar for men $(27.5 \%)$ and women $(27.0 \%)$. The reverse was observed in the urban areas where there were a high proportion of men $(43.6 \%)$ in the wealthiest quintile than women $(32.2 \%)$.

Women in urban and rural areas reported a high prevalence of chronic arthritis/joints pain and chronic back pain (Fig. 1). There was an increasing slope of chronic arthritis/joints pain in both rural and urban women population as age increased; this was much steeper among women than men. A higher prevalence of chronic back pain was reported in urban areas by women. There was no real pattern for rural women with chronic back pain but it was more prevalent at 70-79 years. Generally, the prevalence of chronic arthritis/joints and back pain among rural men was low, even though one would expect a higher prevalence because of the farming activities in those areas. 


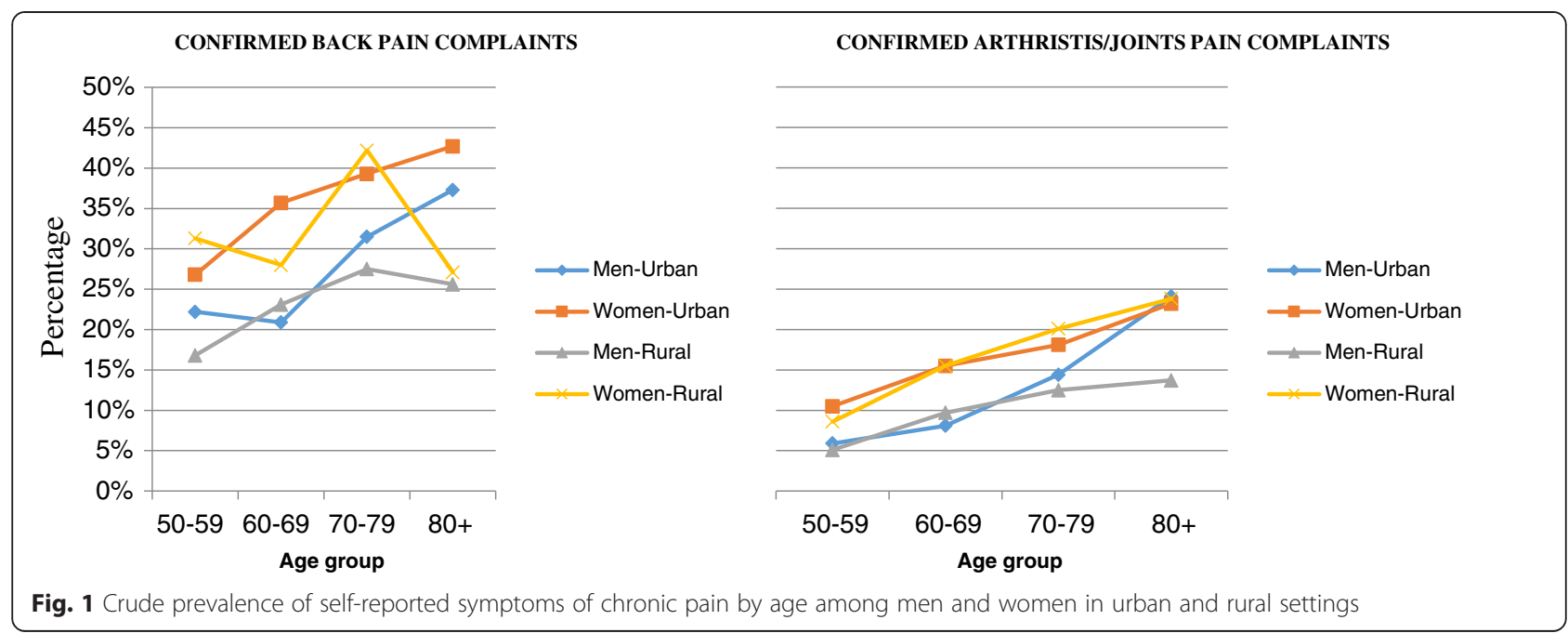

Aged-adjusted prevalence of musculoskeletal disorder (chronic back and chronic arithritis/joint pain) by sex

Table 2 presents age-adjusted prevalence of chronic musculoskeletal disorder among men and women with chronic back and chronic arthritis/joints pain. This is to project the prevalence and variance of prevalence between sexes. In general, chronic back and chronic arthritis/joints pain were more prevalent among women than their male counterparts.

The prevalence of chronic back pain among women with primary education was slightly higher than those with university/postgraduate education $36.2 \%$ (95\% CI; 29.2, 43.3) and $35.2 \%(95 \% \mathrm{CI} ; 16.6,53.9)$ respectively. Also chronic arthritis/joints pain was slightly more prevalent with women who had secondary education than primary education $16.4 \%(95 \% \mathrm{CI} ; 10.3$, 22.5 ) and $15.8 \%$ (95\% CI; 11.1, 20.6). Even though men had lower prevalence compared with women, chronic back pain was more prevalence among men with primary education $29.0 \%$ (95\% CI; 23.4, 34.6) while chronic arthritis/joints pain prevalent was evenly distributed across the education level (see Table 2).

There was no clear difference with the prevalence of chronic back pain and chronic arthritis/joints pain between rural (24.1\%) and urban (24.2 \%). However, chronic back and chronic arthritis/joints pain were more prevalent among women in rural and urban areas when compared with men. Apart from the rural urban dichotomy, type of work was also a prominent determinant of the prevalence of musculoskeletal disorder. Professional men workers and women in technical skills had higher prevalence of back pain 28 \% (95 \% CI; 17.6, 39.2) and 40.8 \% (95\% CI; 31.2, 36.6) respectively. The high prevalence of women in technical skills might be due to the combined role as a mother.

Men who were widowers had a higher prevalence of back and arthritis/joints pain while back pain was more prevalent among women currently married/cohabiting. However, those separated /divorced had a higher prevalence of arthritis/joints pains. Men and women in the middle wealth quintile experienced approximately similar prevalence of back pain. In contrast, women in the wealthiest category had a higher prevalence of arthritis/ joint pain.

Table 3, shows the risk factors associated with chronic back pain and chronic arthritis/joints pain identified using Poisson regression models. The multivariate model indicated that women are more at risk of chronic back pain aIRR $=1.30(95 \% \mathrm{CI} ; 1.11,1.53)$ and chronic arthritis/joints pain aIRR $=1.37(95 \% \mathrm{CI} ; 1.06,1.78)$ compared with their male counterparts after accounting for the effect of other covariates. Men aged 70-79 and 80 years or above are aIRR $=1.41(95 \% \mathrm{CI} ; 1.18,1.68)$ and aIRR $=1.40(95 \% \mathrm{CI} ; 1.11,1.76)$ times more at risk of chronic back pain compare with the 50-59 years age group after accounting for marital status, occupation status and socio-economic status. An age gradient was found for arthritis/joints pain; the incidence rate ratio of chronic arthritis/joints pain increased with age for both men and women. However, there was no gradient for chronic back pain. There was a positive association between socio-economic status and the risk of chronic back pain and chronic arthritis/joints pain. The risk significantly increased with wealth quintile, those with chronic back pain in the middle quintile aIRR $=2.03$ (95\% CI; 1.64, 2.50), the incidence rate ratio was about twice compared with the poorest quintile.

\section{Discussion}

The findings of this study suggest a high prevalence of chronic back and arthritis/joints pain $(28.2 \%$ and $10.7 \%$ respectively), in a nationwide sample of urban and rural elderly men and women. The prevalence of chronic back 
Table 2 Age-Adjusted prevalence of chronic musculoskeletal disorder among men and women

\begin{tabular}{|c|c|c|c|c|c|c|}
\hline & Men & Men & Women & Women & Men & Women \\
\hline \multirow[t]{2}{*}{ Variables } & Total & Back pain & Back pain & Total & Joint pain & Joint pain \\
\hline & N & $\%(95 \% \mathrm{Cl})$ & $\%(95 \% \mathrm{Cl})$ & $\mathrm{N}$ & $\%(95 \% \mathrm{Cl})$ & $\%(95 \% \mathrm{Cl})$ \\
\hline \multicolumn{7}{|l|}{ Educational level } \\
\hline No formal education & 1095 & $21(17.9,24.9)$ & $32.2(28.4,36.1)$ & 1682 & $8.9(6.3,11.5)$ & $14.1(11.2,17.1)$ \\
\hline Primary education & 498 & $29.0(23.4,34.6)$ & $36.2(29.2,43.3)$ & 396 & $9.8(6.4,13.2)$ & $15.8(11.1,20.6)$ \\
\hline Secondary education & 624 & $23.3(18.3,28.4)$ & $32.9(25.1,40.7)$ & 254 & $9.3(6.4,12.2)$ & $16.4(10.3,22.5)$ \\
\hline Uni/postgraduate & 112 & $24.5(14.1,35.0)$ & $35.2(16.6,53.9)$ & 39 & $9.9(3.5,16.3)$ & $11.6(0.6,22.6)$ \\
\hline \multicolumn{7}{|l|}{ Marital status } \\
\hline Never married & 27 & $20.0(2.7,37.4)$ & $28.1(9.4,46.8)$ & 31 & $10.3(-0.9,21.5)$ & $9.4(-2.9,21.8)$ \\
\hline Currently married/cohabiting & 1954 & $24.3(21.3,27.3)$ & $33.7(28.1,39.2)$ & 785 & $10.0(7.9,12.1)$ & $15.8(10.6,21.0)$ \\
\hline Separated/divorced & 191 & $23.8(16.7,30.9)$ & $31.9(26.0,37.7)$ & 433 & $7.4(3.6,11.2)$ & $18.4(14.2,22.6)$ \\
\hline Widowed & 163 & $30.4(19.1,41.62)$ & $32.9(28.5,37.2)$ & 1113 & $14.1(6.1,22.1)$ & $14.0(10.9,17.1)$ \\
\hline \multicolumn{7}{|l|}{ Type of Work } \\
\hline Professionals & 64 & $28.4(17.6,39.2)$ & $16.4(3.9,28.9)$ & 15 & $5.7(0.4,11.0)$ & $13.5(-0.13,27.2)$ \\
\hline Skilled agricultural and fishery workers & 1746 & $26.2(23.1,29.3)$ & $32.9(29.2,36.6)$ & 1341 & $10.6(8.2,13.0)$ & $14.4(11.6,17.2)$ \\
\hline Technical & 193 & $17.9(11.5,29.3)$ & $40.8(31.2,50.4)$ & 168 & $7.8(2.8,12.7)$ & $14.5(6.9,22.1)$ \\
\hline Elementary occupation & 121 & $17.8(10.3,25.2)$ & $32.5(27.3,37.7)$ & 441 & $14.7(6.6,22.8)$ & $14.9(10.7,19.1)$ \\
\hline \multicolumn{7}{|l|}{ Socio-economic status } \\
\hline Poorest & 449 & $12.9(8.5,17.4)$ & $23.7(18.0,29.4)$ & 489 & $6.5(2.2,10.9)$ & $10.1(26.9,13.2)$ \\
\hline Poor & 430 & $23.2(17.1,29.3)$ & $28.8(23.2,34.4)$ & 509 & $9.4(5.9,12.9)$ & $12.3(9.2,15.4)$ \\
\hline Middle & 460 & $37.0(30.5,43.5)$ & $38.3(32.4,44.2)$ & 489 & $9.7(6.1,13.3)$ & $14.9(10.7,19.1)$ \\
\hline Upper fifth & 472 & $21.3(16.8,25.8)$ & $38.3(32.2,44.4)$ & 461 & $9.0(6.3,11.7)$ & $17.6(13.0,22.1)$ \\
\hline Wealthiest & 534 & $24.9(20.0,29.9)$ & $31.8(25.8,37.7)$ & 424 & $14.1(10.1,18.1)$ & $16.9(12.4,21.4)$ \\
\hline \multicolumn{7}{|l|}{ Setting } \\
\hline Rural & 881 & $24.1(20.4,27.9)$ & $32.2(28.0,36.4)$ & 1044 & $10.2(7.3,13.1)$ & $13.8(10.7,16.8)$ \\
\hline Urban & 1466 & $24.2(20.4,27.9)$ & $33.0(28.7,37.3)$ & 1333 & $10.0(7.4,12.5)$ & $15.6(12.0,19.1)$ \\
\hline
\end{tabular}

and chronic arthritis/joints pain is greater among women than their male counterparts across the age groups. Among women however, the rates of chronic arthritis/joints and chronic back pains were observed not to show any variations across the age groupings. For the age group 60 years or above, the prevalence for arthritis/joint pain is relatively low for the urban dwelling women but high in the rural dwelling women, with equilibrium in rates, reached at $80+$ years. Though a number of studies do not find same for study participants in their cases, others have reported a significant association of joint and muscle pain with gender. This was evidenced in a Cape Town study in which it was concluded that the higher prevalence of MSD in women, is a pattern recognized in many chronic musculoskeletal conditions including rheumatoid arthritis(RA), Osteoporosis(OA) and fibro- myalgia [15].

Chronic back pain and chronic arthritis/joints pain were observed to increase with age among women: while it was observed to be on a steep rise to 60 years in urban dwelling women, from where there is a small percentage rise in prevalence till equilibrium is reached at $80+$ years; rural dwelling women exhibited an appreciable rise in prevalence with increasing age. This is consistent with the findings from a study by Urwin et al. (1998), they estimated the prevalence of musculoskeletal disorders at different anatomical sites. They reported in women, the prevalence of musculoskeletal pain at most sites increased with age up to 75 years and then reached a plateau [16]. Women at an older age are more exposed to various risks such as psychological stress, increase blood pressure and chronic diseases. Moreover, they are susceptible to earlier age strike by non-communicable diseases especially in less developed countries [17]. It is possible that most women in their older age continue to carry their grandchildren and participate in heavy work exposing them to chronic back pain and chronic arthritis/joints pain.

In men, it was observed that chronic arthritis/joints pain, though relatively lower in prevalence to that of 
Table 3 Risk factors associated with chronic musculoskeletal disorder in elderly population, Ghana

\begin{tabular}{|c|c|c|c|c|c|c|c|c|}
\hline \multirow[b]{3}{*}{ Variables } & \multicolumn{4}{|c|}{ Chronic back pain } & \multicolumn{4}{|c|}{ Chronic arthristis/joints pain } \\
\hline & \multicolumn{2}{|c|}{ Univariate model } & \multicolumn{2}{|c|}{ Multivariable model } & \multicolumn{2}{|c|}{ Univariate model } & \multicolumn{2}{|c|}{ Multivariable model } \\
\hline & $\mathrm{IRR}^{* *}$ & $(95 \% \mathrm{Cl})$ & $\mathrm{alRR}^{* *}$ & $95 \% \mathrm{Cl}$ & IRR & $95 \% \mathrm{Cl}$ & alRR & $95 \% \mathrm{Cl}$ \\
\hline \multicolumn{9}{|l|}{ Gender } \\
\hline Men & 1.00 & & & & 1.00 & & 1.00 & \\
\hline Women & 1.36 & $1.20,1.54^{*}$ & 1.30 & $1.11,1.53$ & 1.45 & $1.20,1.74^{*}$ & 1.37 & $1.06,1.78^{*}$ \\
\hline \multicolumn{9}{|l|}{ Age group } \\
\hline $50-59$ & 1.00 & & 1.00 & & 1.00 & & 1.00 & \\
\hline $60-69$ & 1.17 & $1.00,1.38^{*}$ & 1.18 & $1.00,1.39$ & 1.48 & $1.15,1.91^{*}$ & 1.50 & $1.15,1.95^{*}$ \\
\hline $70-79$ & 1.43 & $1.21,1.69^{*}$ & 1.41 & $1.18,1.68$ & 2.01 & $1.57,2.57^{*}$ & 2.02 & $1.56,2.62^{*}$ \\
\hline $80+$ & 1.36 & $1.09,1.69$ & 1.40 & $1.11,1.76$ & 2.30 & $1.69,3.14^{*}$ & 2.39 & $1.74,3.30^{*}$ \\
\hline \multicolumn{9}{|l|}{ Settings } \\
\hline Rural & 1.00 & & & & 1.00 & & & \\
\hline Urban & 1.01 & $0.86,1.18$ & & & 1.03 & $0.76,1.40$ & & \\
\hline \multicolumn{9}{|l|}{ Educational level } \\
\hline No formal education & 1.00 & & & & 1.00 & & & \\
\hline Primary education & 1.03 & $0.88,1.21$ & & & 0.86 & $0.65,1.15$ & & \\
\hline Secondary education & 0.84 & $0.69,1.02$ & & & 0.79 & $0.61,1.03$ & & \\
\hline Uni/postgraduate & 0.87 & $0.59,1.27$ & & & 0.72 & $0.41,1.24$ & & \\
\hline \multicolumn{9}{|l|}{ Marital status } \\
\hline Never married & 0.76 & $0.40,1.45$ & 0.76 & $0.38,1.52$ & 0.80 & $0.32,2.04$ & 0.73 & $0.27,1.97$ \\
\hline Currently married/cohabiting & 1.00 & & 1.00 & & 1.00 & & 1.00 & \\
\hline Separated/divorced & 1.18 & $0.99,1.41$ & 1.10 & $0.92,1.32$ & 1.26 & $0.99,1.61$ & 1.15 & $0.88,1.41$ \\
\hline Widowed & 1.34 & $1.17,1.52^{*}$ & 1.10 & $0.93,1.30$ & 1.49 & $1.21,1.83^{*}$ & 1.07 & $0.80,1.43$ \\
\hline \multicolumn{9}{|l|}{ Type of work } \\
\hline Professional & 0.95 & $0.55,1.64$ & 0.15 & $0.67,1.96$ & 0.56 & $0.27,1.19$ & 0.68 & $0.32,1.45$ \\
\hline Skilled agricultural & 1.06 & $0.90,1.24$ & 1.15 & $0.97,1.37$ & 0.90 & $0.67,1.22$ & 1.04 & $0.76,1.41$ \\
\hline Plant & 1.00 & $0.77,1.29$ & 1.08 & $0.83,1.39$ & 0.76 & $0.46,1.25$ & 0.84 & $0.50,1.41$ \\
\hline Elementary occupation & 1.00 & & 1.00 & & 1.00 & & 1.00 & \\
\hline \multicolumn{9}{|l|}{ Socio-economic status } \\
\hline Poorest & 1.00 & & 1.00 & & 1.00 & & 1.00 & \\
\hline Poor & 1.44 & $1.14,1.83^{*}$ & 1.45 & $1.14,1.84^{*}$ & 1.32 & $0.91,1.91$ & 1.32 & $0.92,1.92$ \\
\hline Middle & 2.04 & $1.65,2.52^{*}$ & 2.03 & $1.64,2.51^{*}$ & 1.38 & $0.96,1.99$ & 1.38 & $0.95,2.00$ \\
\hline Upper fifth & 1.58 & $1.23,2.02^{*}$ & 1.62 & $1.27,2.08^{*}$ & 1.43 & $0.99,2.06$ & 1.49 & $1.03,2.17^{*}$ \\
\hline Wealthiest & 1.46 & $1.15,1.85^{*}$ & 1.61 & $1.26,2.06^{*}$ & 1.68 & $1.15,2.44^{*}$ & 1.95 & $1.33,2.85^{*}$ \\
\hline
\end{tabular}

Significance level $* \mathrm{P} \leq 0.05 *$ * $\mathrm{RR}=$ Incidence Rate Ratio and alRR $=$ Adjusted Incidence Rate Ratio

women across same age group, showed general increasing prevalence with age. Across the age groupings for rural dwellers, the prevalence plateaus as against the steep rise in prevalence across the age groups for the urban dwelling males. Men in urban areas also reported a higher prevalence of chronic arthritis/joints pain, especially those 80 years or older. This observation is again in congruence with a study in Burkina Faso that showed a consistent relationship between age and the prevalence of NCD symptoms. However, the significance of this is paralleled by what appears, in terms of health conditions, to be evidence of early aging in the adult population. Chronic arthritis/joints pain and chronic back pain were unexpectedly high among the youngest, and their frequency increased steeply with age up to a prevalence of over $50 \%$ starting in the group aged 55-64 years. These observations converge with those of other studies suggesting that NCDs are both more lethal and developing at earlier ages in sub-Saharan Africa [18]. Again consistency is elicited with a study in India, by, Hirve 
et al. (2010) they concluded that disability in all domains increased with increasing age [19].

In this study, a significant proportion of men $(84.0 \%$ rural and $82.1 \%$ urban) are either currently married or cohabiting. This overwhelming proportion may be characterized by many factors such as biological, psychological and social factors [20]. Generally, men are encouraged to remarry after the loss of their spouse even at an older age while their female counterparts prefer either to care for their children/grand children or stay single. A study conducted in Uganda revealed that over half of the widowers remarry after the loss of their spouse [21]. Also socio-cultural factors limit the participation of men in child raising activities [22] in developing countries, hence most men remarry. The prevalence of chronic back and chronic arthritis/ joints pain were higher among men who were widowers; 30.4 and $14.1 \%$ respectively.

In contrast, a substantial proportion of women is widowed both in rural $(46.0 \%)$ and urban $(47.8 \%)$ areas than their males in rural $(7.0 \%)$ and $(6.8 \%)$ urban areas. It can be deduced from the demographic outcomes that women are living longer as there was a higher proportion of women aged 70 years or above than men (Table 1). This finding is consistent with the global change in the life expectancy of women [17, 23]. For many women, widowhood is a signal of unwanted and unplanned change in social and economic circumstances and in some cultures, it is associated with social stigma [23]. Older women living alone are more likely to be at risk of physical illnesses. The prevalence of chronic back pain of women who were widowed (32.9\%) was comparable to those currently married/cohabiting (33.7 \%). On the other hand, women separated/divorced 18.4 \% (95\% CI; 14.2, 22.6) differed prevalence of chronic arthritis/joint pain with those widowed $14.0 \%$ (95 \% CI; 10.9, 17.1). However, the longer life expectancy of women should not imply, adverse health outcomes [24].

Non-literacy was observed to be higher in rural dwelling women and men and this reflected in their socioeconomic status. Thus the poor rural dwelling women's finding with regards to MSD emphasizes the reality of existing gender biases in relation to economic power, which may be among other factors, the product of lower levels of education and savings, and the poorer life-time earning histories of many women as indicated in the tables. Additionally, the care giving role of women in the society limits workforce participation, contributing to poorer health in older age [25-28]. Per this observation, the cyclical nature of poverty and ill health is highlighted. This study adds to the growing body of evidence that social deprivation is linked not only to mortality but also to morbidity. The results are consistent with those reported recently by the Tanzanian Ministry of Health and Social Welfare, which found that older people make up around one-third of all disabled people and people with decreasing levels of education [29]. Performance and functionality self-reports were similar across all SES quintiles. Self-reports on quality of life were not significantly influenced by sociodemographic variables.

\section{Strength and limitations}

The exploration of the World Health Organization's (WHO) Study on AGEing (SAGE) and Adult Health survey conducted from May 2007 to June 2008 data on Ghana, has allowed for the description of the sex disparities of chronic musculoskeletal disorder burden in an elderly Ghanaian population. The analysis was done with regards to socio-economic and demographic factors as well as symptoms of MSD. The aim of the disintegration analysis was to move beyond a basic comparison of sex differences in self-reported health, and instead begin to unravel the determinants of the differences and variations across contrasting settings and factors. The major strength of the study lies in its design and on the sample studied. Adult population health survey using specific and validated measures of function and generic measures of HRQOL is an adequate method to determine varied aspects of the burden of pain across diagnoses. This increases the generalizability potential of the results. A weakness of the study could be the concurrent diagnosis of other chronic diseases, which might not make our diagnosis, based on self-report accurate. The instrument used to assess self-reported health in this case a questionnaire, might not be able to fully capture people's experiences and expectations for their health. However, this method for measuring health has been used as part of the World Health Survey in some 70 countries with robust results though. It makes both sound economic and social sense to keep the aged fit and healthy; therefore preventive interventions should be implemented in order to help reduce the costs of long-term care for chronic conditions [23].

\section{Conclusion}

The estimated prevalence and risk factors in this paper highlights the urgency of adapting better health systems and services to meet the changing health-care needs of the aged in low-and middle-income countries, primarily by improving the capacity to prevent and manage back pain and arthritis/joints pains. Despite increased use of health services, there is evidence that health services do not necessarily meet all of the needs of the aged. They continue to experience substandard health treatments across a number of non-communicable diseases including back pain and arthritis/joints pain [30, 31]. 
In conclusion, there was a gender variation in musculoskeletal disorder that was significantly higher among women than their male counterparts. Age, marital status and socio-economic status were risk factors associated with musculoskeletal disorder. The risk of back pain and arthritis/joints pain were similar in rural and urban areas.

\section{Policy implication}

Gender disparities in MSD provided by this analysis may be a useful advocacy material to garner increased effort by health and social organizations in the quest to implement gender-based policies in the National Ageing policy of 2010 in Ghana.

As a result of improved health status, life expectancy is anticipated to increase with time. This will lead to a higher proportion of elderly population than we currently have-demographic transition. Programmers and policies makers would have to develop and implement appropriate geriatric care policy and protocols to address this gap increases.

\section{Abbreviations}

SAGE: Study on Global AGEing; MSD: Musculoskeletal disorder; WHO: World Health Organization; ISCO: International standard classification of occupation; RA: Rheumatoid; OA: Osteoporosis; NCD: Non communicable disease; HRQOL: Health related quality of life.

\section{Competing interests}

The authors declare no competing interest. The views expressed in this paper are those of the authors. No official endorsement by the World Health Organization or Ministry of Health of Ghana/Ghana Health Service is intended or should be inferred.

\section{Authors' contributions}

$E K N, E O, V M D, E O D$ and PAB initiated the paper and drafted the initial manuscript. EKN performed the statistical analysis. AEY, GF and SH participated in the large study design and coordinate data collection and helped to draft the manuscript. All authors read and approved the final manuscript.

\section{Acknowledgements}

This study was funded by the US National Institute on Ageing through an interagency agreement with the World Health Organization (OGHA 04034785; YA1323-08-CN-0020; Y1-AG-1005-01). WHO contributed financial and human resources to SAGE Ghana. The Ministry of Health, Ghana, is supportive of SAGE. The University of Ghana's, Department of Community Health contributed training facilities, data entry support, and storage of materials. The Ghana Statistical Office provided the sampling information for the sampling frame and updates. The content is solely the responsibility of the authors and does not necessarily represent the official views of the World Health Organization or Ministry of Health of Ghana. The authors thank Professor Richard Biritwum, the principal investigator for the Ghana site, the Ghana SAGE Team and all data collectors for their assistance with field visits. In addition, we thank the Ghana Ministry of Health and Regional Health Directorates for facilitating work.

\section{Author details}

'Department of Population, Family and Reproductive Health, School of Public Health, Kwame Nkrumah University Science and Technology, Kumasi, Ghana. ${ }^{2}$ Department of Nursing, Faculty of Allied Health Sciences, Kwame Nkrumah University of Science and Technology, Kumasi, Ghana. ${ }^{3}$ Department of Global Health, School of Public Health, Kwame Nkrumah University of Science and Technology, Kumasi, Ghana. ${ }^{4}$ Kumasi Collaborative Center for Tropical Research, Kumasi, Ghana. ${ }^{5}$ Department of Occupational and Environmental Health, School of Public Health, Kwame Nkrumah University
Science and Technology, Kumasi, Ghana. ${ }^{6}$ Department of Community, College of Health Sciences, University of Ghana, School of Public Health, Korle-Bu, Accra, Ghana. ${ }^{7}$ Noguchi Memorial Institute for Medical Research, College of Health Sciences, University of Ghana, Legon, Accra, Ghana.

${ }^{8} \mathrm{College}$ of Health Sciences, University of Ghana School of Medicine and Dentistry, Korle-Bu, Accra, Ghana.

Received: 23 January 2015 Accepted: 10 August 2015

Published online: 19 August 2015

\section{References}

1. United Nations DoEaSA. World population ageing 2009. New York: United Nations; 2010

2. The Disease Control Priorities Project. Global burden of disease and risk factors. Washington: The Disease Control Priorities Project; 2006

3. Bloom DE, Cafiero ET, Jané-Llopis E, Abrahams-Gessel S, Bloom LR, Fathima $\mathrm{S}$, et al. The global economic burden of noncommunicable diseases. Geneva: World Economic Forum; 2011.

4. Woolf AD, Pfleger B. Burden of major musculoskeletal conditions. Bull World Health Organ. 2003;81:646-56.

5. Elliot T, Renier C, Palcher J. Chronic pain, depression, and quality of life: correlations and predictive value of the SF-36. Pain Med. 2003:4:331-9.

6. Mantyselka P, Kumpusalo E, Ahonen R, Kumpusalo E, Kauhanen J, Viinamaki $\mathrm{H}$, et al. Pain as a reason to visit the doctor: a study in Finnish primary health care. Pain. 2001;89:175-80.

7. Elliot A, Smith B, Hannaford P, Chambers W. The course of chronic pain in the community: results of a 4-year follow-up study. Pain. 2002;99:299-307.

8. Gatchel R. Musculoskeletal disorders: primary and secondary interventions. J Electromyogr Kinesiol. 2004;14:161-70.

9. Ekpenyong CE, Udokang N, Akpan EE, Samson TK. Double burden, Non-communicable diseases and risk factors evaluation in Sub-Saharan africa: the Nigerian experience. European Int J Sustain Dev. 2012;1 (2):249-70.

10. Sutthichai J, Chaiyos K, Wiput P, Paibul S, Shah E. Determining public health priorities for an ageing population: the value of a disability survey. Southeast Asian J Trop Med Public Health. 2003;34:4.

11. Kowal P, Chatterii S, Naidoo N, Biritwum R, Fan W, Lopez Ridaura R, et al. Data resource profile: the World Health Organization study on global AGEing and adult health (SAGE). Int J Epidemiol. 2012;41 (6):1639-49.

12. International Labor Organization (ILO): International Standard Classification of Occupations (ISCO-88). www.lo.org/public/english/bureau/stat/isco/ index.htm.

13. Service GS. Population and housing census. Accra: Ghana Statistical Service; 2010. p. 2012

14. Zou G. A modified poisson regression approach to prospective studies with binary data. Am J Epidemiol. 2004;159(7):702-6.

15. Parker R, Jelsma J. The prevalence and functional impact of musculoskeleta conditions amongst clients of a primary health care facility in an underresourced area of Cape Town. BMC Musculoskelet Disord. 2010;11:2.

16. Urwin M, Symmons D, Allison T, Brammah T, Busby H, Roxby M, et al. Estimating the burden of musculoskeletal disorders in the community: the comparative prevalence of symptoms at different anatomical sites, and the relation to social deprivation. Ann Rheum Dis. 1998;57(11):649-55.

17. Stevens GA, Mathers CD, Beard JR. Global mortality trends and patterns in older women. Bull World Health Organ. 2013;91(9):630-9.

18. Miszkurka M, Haddad S, Langlois EV, Freeman EE, Kouanda S, Zunzunegui MV. Heavy burden of non-communicable diseases at early age and gender disparities in an adult population of Burkina Faso: World Health Survey. BMC Public Health. 2012;12:24

19. Hirve $S$, Juvekar $S$, Lele $P$, Agarwal D. Social gradients in self-reported health and well-being among adults aged 50 and over in Pune District, India. Global Health Action. 2010;3.

20. DeLamater JD, Sill M. Sexual desire in later life. J Sex Res. 2005;42(2):138-49.

21. Ntozi JP. Widowhood, remarriage and migration during the HIV/AIDS epidemic in Uganda. Health Trans Review : Cultural Soc Behavioural Determinants Health. 1997;7(Suppl):125-44.

22. Jorosi-Tshiamo WB, Mogobe KD, Mokotedi MT. Male involvement in child care activities: a review of the literature in Botswana. Afr J Reprod Health. 2013;17(4):35-42

23. World Health Organization. Women and health: Today's evidence tomorrow's agenda. Geneva: WHO; 2009. http://www.who.int/gender/ women_health_report/full_report_20091104_en.pdf. 
24. Davidson MP, DiGiacomo M, McGrath JS. The feminization of aging: how will this impact on health outcomes and services? Health Care Women Int. 2011;32(12):1031-45.

25. Byles J, Feldman S, Mishra G. For richer, for poorer, in sickness and in Health: Older widowed women's health, relationships and financial security. Women Health. 1999;29(1):15-30.

26. Lowe J, Young AF, Dolja-Gore X, Byles J. Cost of medications for older women. Australia New Zeal J Public Health. 2008;32(1):89.

27. Navaie-Waliser M, Spriggs A, Feldman PH. Informal caregiving: Differential experiences by gender. Med Care. 2002;40:1249-59.

28. Parrott TM. Bringing gender into our discussion of policy issues. Gerontol Geriatr Educ. 2002;22(4):57-68.

29. Welfare MoHaS. Johannesburg: World Bank; 2009. Tanzania Disability Survey 2008. Dar es Salaam: National Bureau of Statistics; 2009.

30. Raymond SU, Greenberg HM, Leeder SR. Beyond reproduction: women's health in today's developing world. Int J Epidemiol. 2005;34(5):1144-8.

31. Beaglehole R, Reddy S, Leeder SR. Poverty and human development: the global implications of cardiovascular disease. Circulation. 2007;116(17):1871-3

\section{Submit your next manuscript to BioMed Central and take full advantage of:}

- Convenient online submission

- Thorough peer review

- No space constraints or color figure charges

- Immediate publication on acceptance

- Inclusion in PubMed, CAS, Scopus and Google Scholar

- Research which is freely available for redistribution 